3. PWC. The world in 2050. Disponível em https://www.pwc.com/gx/ en/issues/the-economy/assets/world-in-2050-february-2015.pdf. Acessado em 25/6/17.

4. OECD. GDP long term forecast. Disponível em https://data.oecd.org/ gdp/gdp-long-term-forecast.htm. Acessado em 25/6/17.

5. Shike, D. W. "Beef cattle feed efficiency". Driftless Region Beef Conference 2013. Disponível em: http://lib.dr.iastate.edu/cgi/viewcontent.cgi?article $=1027 \&$ context $=$ driftlessconference. Acessado em 24/6/2017.

6. FAOSTAT/FAO. Disponível em http://www.fao.org/faostat/en/\#home. Acessado em 25/6/2017.

7. Bruinsma, J. The resource outlook to 2050: by how much do land, water use and crop yields need to increase by 2050? Expert Meeting on How to Feed the World in 2050. Rome, FAO and ESDD. Disponível em ftp://ftp.fao.org/docrep/fao/012/ak542e/ ak542e06.pdf. Acessado em 25/6/2017.

8. The World Bank. Arable Land (Hectares per person). Disponível em http://data.worldbank.org/indicator/AG.LND.ARBL.HA.PC. Acessado em 25/6/2017.

9. IPCC. Quinto Informe de Evaluación del IPCC: Cambio Climático. Disponível em https://www.ipcc.ch/report/ar5/index_es.shtml. Acessado em 24/6/2017

10. Wezel, A.; Soldat, V. "A quantitative and qualitative historical analysis of the scientific discipline agroecology". International Journal of Agricultural Sustainability, p. 3-18, 7, 1, 2009.

11. Guterres, I. Agroecologia militante. Editora Expressão Popular, 2006. Disponívelemhttp://xa.yimg.com/kq/groups/22192126/1226852867/ name/Agroecologia+Militante.PDF. Acessado em 25/6/2017.

12. Gazzoni, D. L. "Questionando dogmas I". Cultivar Grandes Culturas, 18, 213, 2017.

13. Gazzoni, D. L. "Questionando dogmas II". Cultivar Grandes Culturas, 18, 214, 2017.

14. Seufert, V.; Ramankutty, N.; Foley, J. A. "Comparing the yields of organic and conventional agriculture". Nature, p. 229-232, 485, 2012.

15. Portal Brasil. "Agricultura familiar produz $70 \%$ de alimentos do país, mas ainda sofre na comercialização". Disponível em http://www.brasil.gov.br/economia-e-emprego/2011/07/agricultura-familiar-precisa-aumentar-vendas-e-se-organizar-melhor-diz-secretario. Acessado em 25/6/2017.

16. Hoffmann, R. "A agricultura familiar produz $70 \%$ dos alimentos consumidos no Brasil?". Disponível em http://coral.ufsm.br/ppgagr/images/Documentos/AF70.pdf. 2014. Acessado em 24/06/2017.

17. le Page, M. "Stop buying organic food if you really want to save the planet". New Scientist. Disponível em https://www.newscientist. com/article/mg23231022-900-stop-buying-organic-food-if-you-really-want-to-save-the-planet/. Acessado em 25/6/2017.

18. Tuomisto, H. L.; Hodge, I. D.; Riordan, P.; Mcdonald, D. W. “Does organic farming reduce environmental impacts? A meta-analysis of European research". J. Environ. Manag., p. 309-320, 112, 2012.

19. McGee, J. A. "Does certified organic farming reduce greenhouse gas emissions from agricultural production?" Agriculture and Human Values, p. 255-263, 32, 2, 2015.

20. Smith-Spangler, C. et al. "Are organic foods safer or healthier than conventional alternatives? A systematic review". Annals of Internal Medicine, p. 348-366, 157, 5. 2012.

21 United Nations. Right to Food. Disponível em https://www.unscn.org/ uploads/web/news/A-71-282-Nutrition-EN.pdf. Acessado em 25/6/17

\section{MEIO AMBIENTE: A SALVAÇÃO PELA LAVOURA}

\author{
Evaristo Eduardo de Miranda
}

INTRODUÇÃO Muitos estudos ecológicos da agricultura brasileira interessam-se apenas pelo impacto ambiental dos sistemas de produção, sem considerar as áreas não exploradas e mantidas em vegetação nativa pelos produtores rurais, com as quais as áreas produtivas interagem. Os impactos e interaçōes entre essas duas realidades, áreas exploradas e preservadas, são permanentes e dinâmicos, positivos e negativos. A compreensão dos processos ambientais na agricultura não pode prescindir dessa visão de conjunto das áreas exploradas e preservadas nos imóveis rurais. Sem essa perspectiva, mais abrangente e totalizante dos imóveis, não é possível analisar os fenômenos que interessam ao conjunto da agropecuária nacional, nem a dimensão territorial de sua organização econômica, agronômica e tecnológica.

Contudo, as análises ainda serão insuficientes quando limitadas a amostras de imóveis rurais. Tanto as áreas preservadas como as de uso permanente adquirem outra dimensão quando consideradas na escala de paisagem, bacia hidrográfica, região, bioma, país e até do planeta. Pesquisas multiescalares da dimensão territorial da agricultura, do local ao global, representam um grande desafio científico. Em ecologia, como na física, a escala cria o fenômeno [1].

Estudos da dimensão ambiental da agropecuária brasileira, em diversas escalas espaciais e temporais, com base apenas em dados censitários e numéricos também são insuficientes, em face de tais realidades territoriais. A compreensão desses fenômenos implica no emprego de novos instrumentos, como o monitoramento orbital e aerotransportado (aeronaves, vants, drones), no uso de sensores cada vez mais sofisticados (multiespectrais, radar, hiperespectrais etc.) e de geotecnologias para ordenar, explorar e publicar, em bases territoriais coerentes, os resultados obtidos [2]. É o que diversas equipes, sobretudo em centros regionais e temáticos da Embrapa, vêm desenvolvendo nas últimas décadas e têm como prioridade em seus cenários de futuro.

Esse conjunto crescente de sensores terrestres, aéreos e orbitais, públicos e privados, para o monitoramento da agricultura, gera um enorme fluxo de dados digitais (petabytes) e exige grandes capacidades computacionais para armazenar, gerir e tratar com confiabilidade essas informações, em tempo adequado (bigdata) [3]. As evoluções no emprego desses recursos têm sido constantes no monitoramento do uso e ocupação das terras. Elas não serão objeto de detalhamento neste artigo, mas delas depende boa parte dos resultados aqui apresentados.

As análises multiescalares da agricultura consideram desde dimensōes locais até internacionais, dadas as interconexōes das atividades sociais, econômicas e ambientais. População, longevidade, 
renda e consumo de alimentos crescem em todo o planeta. E trazem, entre outros desafios, o de alimentar e vestir um adicional de mais de dois bilhões de pessoas nos próximos 40 anos. A produção brasileira de alimentos já atende à necessidade básica de alimentação de mais um bilhão de pessoas. O país está entre os líderes mundiais na produção e/ou exportação de soja, carne bovina, frango, açúcar, café, laranja, milho e outros. A agricultura nacional também é grande produtora de agroenergia (combustíveis sólidos, líquidos, gasosos e energéticos) e de fibras vegetais e animais [4].

A liderança mundial da agricultura do Brasil não é apenas o resultado de grandes produçôes e, sim, de sustentabilidade e competitividade, derivadas da incorporação constante de tecnologias modernas e inovadoras, acompanhadas de ações de conservação dos recursos naturais. No mundo globalizado, não basta produzir: é preciso ser competitivo em preço e qualidade. Não basta aumentar a produtividade: é preciso incrementar a conservação de solo, água, flora, fauna e reduzir/eliminar a utilização de insumos agressivos ou impactantes no meio ambiente. É preciso também definir e manter áreas destinadas à preservação da vegetação nativa e da biodiversidade nos imóveis rurais. E cabe à pesquisa e ao planejamento avaliar esses processos e resultados em escalas regional, nacional e internacional.

Esse esforço de inteligência territorial tem sido possível, no Brasil, com inovações metodológicas próprias e adequadas para as condições nacionais. As análises territoriais decorrentes trazem uma visão complementar da magnitude do componente ecológico e ambiental característico da agropecuária brasileira, nem sempre conhecido [5].

\section{A COMPLEXIDADE DO ESPAÇO RURAL Talvez a pri-} meira imagem ou percepção que se tenha do monitoramento por satélites da agropecuária nacional é sua enorme diversidade. Ela é o resultado de relações sociais complexas e históricas, entre os homens, através da natureza. A agricultura brasileira é plural. Constituída de muitas agriculturas, diferenciadas entre si por processos históricos, localização geográfica, sistemas de produção, condições socioeconômicas, ambientais e agrárias, origens e tradiçôes dos produtores rurais, ela não admite generalizações, nem socioeconômicas, nem tecnológica e ambiental.

Em todo o país, duas realidades espaciais coexistem nos imóveis rurais, com situações intermediárias e cambiantes: as áreas exploradas, onde em geral houve a erradicação da vegetação original pelos sistemas agrossilvopastoris, e as áreas não exploradas, onde a vegetação nativa é mantida em diversos graus de conservação e proteção. São situações inconfundíveis e inseparáveis no meio rural brasileiro.

No caso das áreas não exploradas, boa parte é o resultado da consciência ambiental dos produtores rurais, de seus sistemas de produção, construídos historicamente de forma adequada aos diversos biomas e ecossistemas do país, desde o início do povoamen- to português, ao contrário do que muitos pensam por ignorância histórica [6]. Hoje, parte das áreas destinadas à manutenção da vegetação nativa também é exigida pela legislação ambiental, pelo Código Florestal Brasileiro [7]. Esse conjunto de áreas destinadas à preservação da vegetação nativa nos imóveis rurais representa um enorme desafio de gestão territorial e um custo considerável para os produtores rurais em termos de capital imobilizado e de gastos com a sua manutenção e proteção.

Nas áreas exploradas, assiste-se, há décadas e em todo o país, a uma grande evolução nos sistemas de exploração e produção, marcados pela intensificação (ganhos de produtividade no trabalho, nos insumos e na área) e pela busca da competitividade e rentabilidade. Os sistemas de produção intensificados buscam ser cada vez mais integrados, verticalizados, amigos da biodiversidade, sustentáveis, eficientes e diversificados. Eles contribuem de forma positiva na preservação da vegetação nativa e da biodiversidade, na manutenção da qualidade das águas e na proteção dos solos, como se verá a seguir. E são convergentes em seus impactos ambientais positivos e sinergias, viabilizando até três cultivos no mesmo local e ano, adquirindo dimensões de sustentabilidade sem precedentes na última década.

Esses dois universos constitutivos da agropecuária nacional serão percorridos a seguir, de forma sintética, com ênfase em suas dimensões ambientais, de forma sucessiva, por uma questão de clareza de exposição.

ÁREAS DESTINADAS À EXPLORAÇÃO Sistemas de produção agropecuária próximos do Neolítico, sobretudo em determinados locais da Amazônia e do semiárido nordestino, ainda coexistem com os processos de urbanização, de generalização da comunicação e com a chamada modernização ampliada da agricultura ocorrida nas últimas décadas [8]. Dada a pluralidade da agricultura nacional, não é simples destacar os elementos essenciais de seus desdobramentos ambientais.

Não se tratam de epifenômenos. Dessas inovaçôes, de grande dimensão territorial, resultam ganhos significativos para a proteção dos recursos naturais e a melhoria da qualidade dos alimentos e das condições de produção. Apenas a título de clareza de exposição, apresenta-se a seguir um resumo de uma série de técnicas, tecnologias e sistemas de produção, inovadores e promotores da sustentabilidade, praticados em grande escala territorial pela agricultura brasileira.

Plantio direto na palha, sem aração da terra - $\mathrm{O}$ país produz cereais, leguminosas, oleaginosas e algodão sem arar a terra. São quase 40 milhões de hectares cultivados pelo sistema de "plantio direto na palha”, graças ao desenvolvimento de máquinas apropriadas e insumos adequados.

Redução das emissóes de CO2 e no uso de diesel - O plantio direto na palha evita gradagem e aração. Ele preserva os solos ao 
não movimentá-los e ao favorecer a manutenção de sua cobertura com palha e matéria orgânica. E traz uma enorme economia de combustível. Sem a aração, a redução é da ordem de $40 \%$ nas emissões de $\mathrm{CO} 2$.

Conservação de solos e água - Por não movimentar, nem pulverizar a terra, o plantio direto facilita a infiltração das águas de chuva e reduz a erosão, uma das principais razões da criação dessa tecnologia. Muitos agroquímicos, pouco solúveis em água, chegavam aos rios e aos reservatórios junto com a terra, carreada pelas chuvas.

Gestão da fertilidade dos solos - O Brasil é o quarto mercado consumidor de fertilizantes do planeta (35 milhóes de ton/ano), com $6 \%$ do consumo mundial, atrás da China (33\%), Índia (17\%) e EUA (12\%). Inovações da pesquisa favorecem cada vez mais os processos de fixação biológica de nitrogênio no solo e sua remineralização com o uso de pó de rochas. Rotação de cultivos, integração lavoura-pecuária-floresta, gestão da palha e matéria orgânica (adubos verdes) são cada vez mais viáveis e eficientes.

Benefícios ambientais dos OGMs - A pesquisa pública e privada em genética e biotecnologia desenvolve novas variedades de organismos geneticamente modificados (OGMs) voltadas para a melhor adequação dos cultivos às condiçôes ambientais (baixa fertilidade, seca, ataques de pragas) e à melhor qualidade nutricional e funcional dos alimentos. O Brasil cultivou 49,1 milhōes de hectares com culturas transgênicas na safra 2016/2017, o maior incremento em área plantada no mundo. A agricultura brasileira fica atrás apenas dos Estados Unidos (70,9 milhões de ha) no ranking mundial. Estima-se que só a redução nos tratamentos com defensivos, promovida pelos OGMs (menos passagens para pulverização, menor uso de combustível e produtos fitossanitários), resulta no abatimento anual da emissão de 6,3 bilhôes de quilos de $\mathrm{CO} 2$, o equivalente à remoção de 2,8 milhões de carros de circulação durante um ano [9].

Carne carbono neutro - $\mathrm{O}$ melhoramento genético de animais adaptados às condiçôes tropicais e ambientais dos biomas tem longa tradição no Brasil. Toda uma linha de produtos e técnicas contempla aleitamento, recria, engorda e reprodução; estimula a flora do rúmen; melhora o aproveitamento da pastagem pelo animal; reduz a idade de abate; aumenta a natalidade e diminui a quantidade de carbono e metano emitida na produção de carne. Em áreas de pastagens nativas (cerrados, caatinga, pampa e campos de altitude), o rebanho contribui na conservação da vegetação, coabita com a biodiversidade natural e explora uma fração ínfima do carbono retirado anualmente pela vegetação da atmosfera.

ILPF e a COP 21 - O país do boi verde, do boi de pasto, ampliou a recuperação de pastagens e solos pelo sistema de integração lavoura-pecuária-floresta (ILPF) com manejo, adubação, sombreamento e outras técnicas, que também favorecem o bem-estar animal. Com esse esforço dos produtores rurais já foi atingida a meta de redução de emissões de gases de efeito estufa, assumida pelo Brasil na COP 21 em Paris para 2030: o sequestro de 35 bilhôes de toneladas de dióxido de carbono equivalente.
Tratamento e reciclagem de resíduos dos insumos agrícolas No Brasil, os agricultores devolvem - de forma adequada - mais de $90 \%$ das embalagens de agroquímicos utilizados, um recorde mundial. Podem ser encaminhadas para reciclagem 95\% das embalagens colocadas no mercado, desde que tenham sido corretamente lavadas no momento de uso do produto no campo. As embalagens não laváveis ( $5 \%$ do total) ou não devidamente lavadas são encaminhadas a incineradores credenciados.

Florestas poupadas pela intensificação da agricultura - Em 1972, a safra de grãos foi de 30 milhões de toneladas para uma área plantada de 28 milhões de ha. Em 2016, a produção ultrapassou 210 milhões de toneladas para uma área de 50 milhões de ha. A área cultivada cresceu $80 \%$ e a produção mais de $500 \%$. Esse crescimento "vertical" da produção evitou o desmatamento de mais de 100 milhões de ha de florestas e cerrados.

\section{AS ÁREAS DESTINADAS À PRESERVAÇÃO AMBIENTAL Até 2014, os} únicos números sobre áreas destinadas à preservação da vegetação nativa nos imóveis rurais eram os provenientes do censo agropecuário, do IBGE (Instituto Brasileiro de Geografia e Estatística). Mas algumas questôes permaneciam em aberto, tais como: qual a área de vegetação preservada no interior dos imóveis rurais? Quanto da área agrícola do Brasil está destinado à preservação ambiental? Seria possível mapear e quantificar esse fenômeno em escalas sucessivas: imóveis rurais, municípios, microrregiōes, estados, regiōes e país? Existiriam padrões de repartição territorial das áreas destinadas à preservação da vegetação nos imóveis rurais brasileiros?

A possibilidade do conhecimento atualizado das áreas efetivamente utilizadas e preservadas pela agricultura nos imóveis rurais teve um avanço significativo com o advento do Cadastro Ambiental Rural (CAR). Ele é um dos frutos relevantes do novo Código Florestal, a Lei 12.651 , de 25 de maio de 2012.

Cadastro Ambiental Rural - O CAR é um registro eletrônico, obrigatório para todos os imóveis rurais, e constituiu um relevante instrumento do planejamento agrícola, ambiental e econômico. Até 31 de dezembro de 2016, mais de 3,92 milhões de imóveis rurais, totalizando 399.233.861 hectares, estavam inseridos no Sistema Nacional de Cadastro Ambiental Rural (Sicar). Até 30 de abril de 2017, 4.104.247 de imóveis rurais, totalizando 407.999.690 hectares, estavam inscritos no sistema.

Cada produtor rural, ao cadastrar seu imóvel, preenche uma série de fichas, mapeia o uso e a ocupação das terras em seu imóvel, com base em imagem de satélite de alta resolução. Assim, além de dados alfanuméricos, o CAR reúne informações em base cartográfica, como o perímetro do imóvel e, no seu interior, o mapeamento de: áreas ocupadas, de preservação permanente (APP), reserva legal, servidōes, construções, de interesse social, de utilidade pública etc. São 18 categorias de uso e ocupação das terras geocodificadas em cada imóvel.

Integração dos dados do CAR - No início de 2017, o Grupo de Inteligência Territorial Estratégica (Gite) da Embrapa Monitora- 


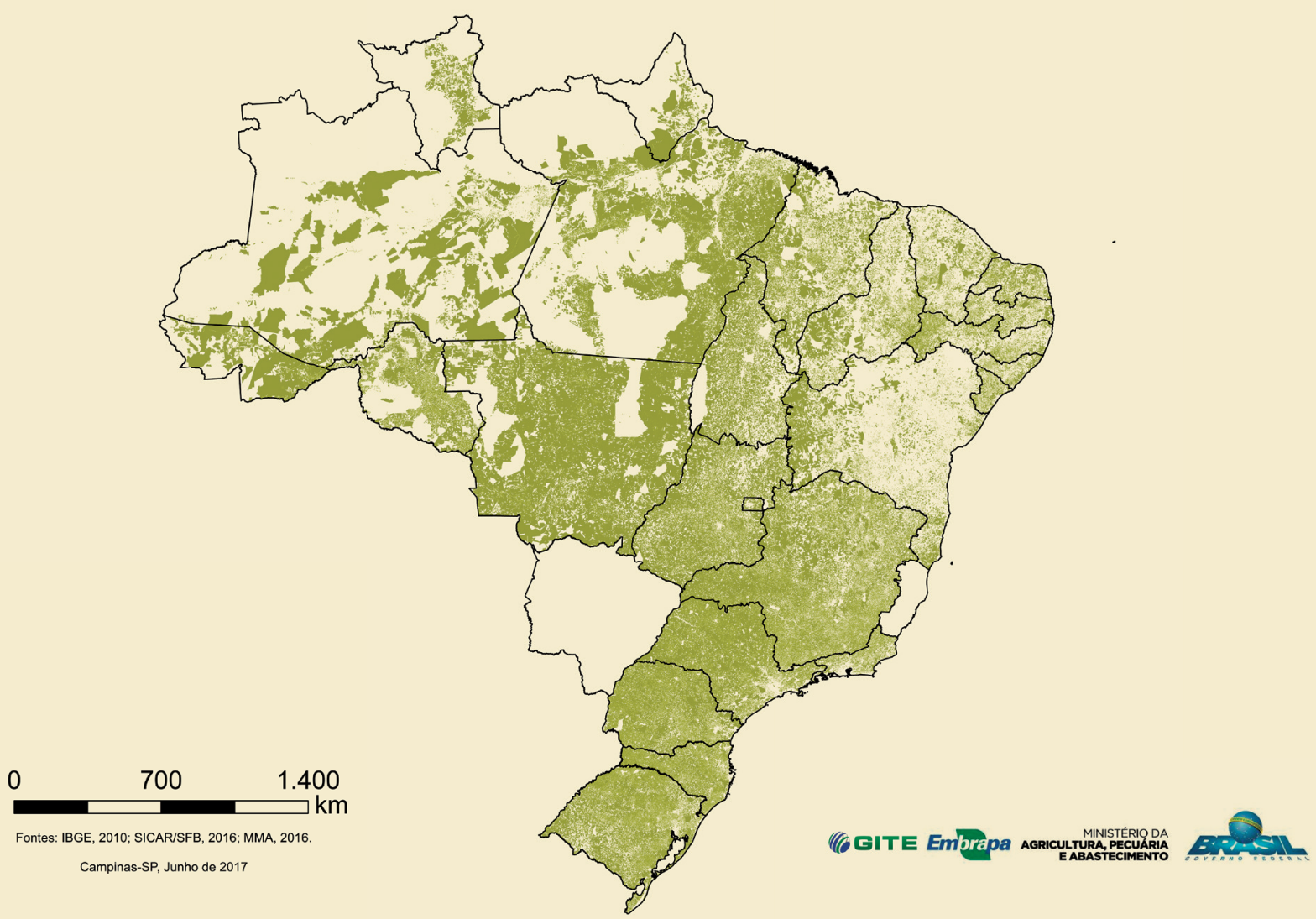

Figura 1. Área mapeada de vegetação preservada nos imóveis rurais do CAR migrados ao Sicar, sem Espírito Santo e Mato Grosso do Sul (2016)

mento por Satélite integrou ao seu Sistema de Inteligência Territorial Estratégica, em Campinas, os dados geocodificados completos e disponíveis do Cadastro Ambiental Rural no Sicar [10]. Com esse enorme banco de dados, pela primeira vez, abriu-se a perspectiva de qualificar e quantificar as áreas de vegetação preservadas nos imóveis rurais com base em mapas, delimitados sobre imagens de satélite com $5 \mathrm{~m}$ de resolução espacial. E não apenas em declaraçôes de produtores transcritas em questionários, como ocorre nos censos do IBGE. Em cada registro do CAR, além do perímetro, o agricultor delimitou cartograficamente: remanescentes de vegetação nativa, áreas de preservação permanente, de uso restrito, consolidadas e reserva legal, conforme determina o Código Florestal [7].

Adesão ao CAR - Quantos imóveis rurais deveriam se cadastrar no CAR? O censo do IBGE de 2006 registrou 5.175.636 estabelecimentos agrícolas no Brasil. Até o final de 2016, um total de 3.923.689 imóveis rurais estava cadastrado no Sicar, 75,8\% do esperado, tendo o censo de 2006 como a base comparativa. As 1.251.947 unidades ainda não cadastradas estavam localizadas essencialmente no Nordeste [11].
Tratamento dos dados do CAR - O enorme e complexo conjunto de dados geocodificados do CAR colocou desafios inéditos. Um deles foi de ordem metodológica, pois nunca dados dessa natureza estiveram disponíveis e não existiam métodos e procedimentos de tratamento de informação consagrados e validados a serem aplicados neste caso. A equipe totalizou, a partir dos dados cartográficos, as áreas de preservação permanente, as reservas legais e os remanescentes de vegetação excedentes declarados em cada imóvel e retirou sobreposiçôes intra e inter cadastros. Os métodos empregados (geoprocessamento e procedimentos estatístico-matemáticos), bem como os resultados numéricos e cartográficos para cada microrregião, estado, região e país, estão disponíveis no site do Gite.

Principais resultados - Os resultados ainda não estão completos. Até maio de 2017, em que pese a existência de 37.608 agricultores cadastrados no CAR estadual do Mato Grosso do Sul e 40.828 agricultores cadastrados no CAR estadual do Espírito Santo, seus dados não estavam disponíveis no Sicar. Nesse sentido, o valor absoluto das áreas de vegetação preservada nos imóveis em todo o país segue subestimado. 
Os resultados já obtidos mostram uma significativa e subestimada participação da agricultura na preservação do meio ambiente. No final de 2016, um total medido e estimado de 176.806 .937 hectares estava destinado à preservação e manutenção da vegetação nativa pelos agricultores nos imóveis rurais, o que equivale a 20,5\% do território nacional (ou 22\% quando excetuadas as áreas dos estados Mato Grosso do Sul e do Espírito Santo, cujos dados ainda não foram integrados ao Sicar). $\mathrm{O}$ total das áreas destinadas à preservação da vegetação nativa representa $47,7 \%$ da área total dos imóveis cadastrados no Sicar.

A unificação cartográfica homogênea de todas as áreas de vegetação preservadas no interior dos imóveis rurais e cadastradas no Sicar até dezembro de 2016 pode ser observada na Figura 1.

A equipe do Gite também mapeou e calculou as áreas preservadas pelos imóveis rurais para os estados e em cada uma das 558 microrregiôes homogêneas do Brasil. $\mathrm{O}$ detalhamento das áreas preservadas mapeadas e medidas em cada microrregião e em cada um dos 25 estados também está disponível para consulta em tabelas específicas, estado por estado, no site do projeto.

Os valores obtidos diferem bastante entre as regiōes do país. Um resumo é dado a seguir, comparando as áreas destinadas à preservação da vegetação nativa com as áreas protegidas em unidades de conservação e terras indígenas, segundo os dados oficiais do Ministério de Meio Ambiente e da Funai (Fundação Nacional do Índio).

No Sul, as unidades de conservação e terras indígenas protegem $2 \%$ da região. Nos imóveis rurais, os produtores preservam o equivalente a $17 \%$ da região, oito vezes mais. E dentro da área cadastrada, os produtores preservam 26\% das terras, número superior à exigência do Código Florestal.

No Sudeste, ainda sem os dados do Espírito Santo, os produtores preservam em seus imóveis $17 \%$ da região em vegetação nativa contra $4 \%$ em áreas protegidas. Na área rural, eles preservam 29\% de suas terras, número também superior à exigência da legislação ambiental.

No Centro-Oeste, sem os dados do Mato Grosso do Sul, os produtores preservam em seus imóveis 33\% da região, contra 14\% em áreas protegidas. Isso corresponde a $49 \%$ de suas terras, praticamente a metade, número bem superior à demanda do Código Florestal.

No Norte, no Tocantins, a agricultura preserva o dobro da área total das unidades de conservação e terras indígenas: $20 \%$ contra $10 \%$. Nos imóveis, os produtores apresentam uma taxa de preservação da vegetação nativa de $56 \%$. Esse é o único estado da região não inserido integralmente no bioma Amazônia. Nos estados amazônicos, a proteção ambiental é muito abrangente: 71\% do Amapá, 53\% do Amazonas e 50\% do Pará, além de amplos territórios recobertos por floresta tropical em terras devolutas.

No Nordeste, ainda faltam muitas áreas cadastráveis, mas para indicar o papel dos agricultores na preservação da vegetação, os dados disponíveis já bastam. Na maioria dos estados nordestinos, os produtores preservam mais de $50 \%$ da área de seus imóveis, quando a exigência é de $20 \%$ (salvo em parte do Maranhão). A área preserva- da pela pequena parcela de agricultores cadastrados no CAR (34\%) até 2016 , já representava cerca de $20 \%$ da região, enquanto as áreas protegidas conservam menos de $10 \%$.

O panorama é o mesmo em todas as regiōes do Brasil. Quando considerados em seu conjunto, os produtores rurais preservam em vegetação nativa uma parcela sempre superior à exigida pelo Código Florestal nos imóveis, que é de no mínimo 20\%, em grande parte do Sul, Sudeste, Nordeste e Centro-Oeste. Isso mesmo sem considerar o direito de milhões de produtores a possuírem percentuais menores de áreas de vegetação preservadas por terem desmatado em conformidade com a legislação do tempo em que ocorreu essa conversão (artigo 68 do Código Florestal), ou porque o tamanho reduzido de seus imóveis (abaixo de quatro módulos fiscais) permite tal situação.

As análises dos dados do CAR ainda serão objeto de atualizaçóes, pois devem sofrer algumas mudanças. Além da futura incorporação dos dados do Espírito Santo e do Mato Grosso do Sul, um residual de agricultores, sobretudo pequenos, ainda está se cadastrando e os números terão pequenas alterações até o final deste ano, quando termina o prazo do cadastramento. Em breve, os Programas de Regularização Ambiental (PRA) sucederão o CAR. Sua aplicação progressiva também trará mais um aumento no valor das áreas destinadas à preservação da vegetação nativa no meio rural.

CONCLUSÕES A compreensão das questôes ambientais na agricultura não pode prescindir de uma visão integrada do conjunto das áreas exploradas e preservadas nos imóveis rurais brasileiros, no seu entorno e fora deles (unidades de conservação, terras indígenas ou terras devolutas). Trabalhos de inteligência e gestão territorial do Gite da Embrapa indicam o papel decisivo e inigualável da agropecuária brasileira na preservação ambiental.

Nas áreas exploradas, os ganhos ambientais, dentro e fora dos imóveis rurais, cresceram muito graças às inovações tecnológicas que acompanham a modernização da agricultura. A pesquisa agropecuária, pública e privada, desenvolveu um conjunto de técnicas e tecnologias inovadoras voltadas para a busca da sustentabilidade e da competitividade, conceitos que são cada vez mais sinônimos face às exigências do mercado consumidor.

Entre elas, destacam-se: reciclagem de resíduos, fixação biológica de nitrogênio, sistemas de plantio direto, controle integrado de pragas e doenças, espécies geneticamente modificadas, sistemas alternativos de produção orgânica, integração lavoura-pecuáriafloresta, novas técnicas de irrigação, recuperação de pastagens degradadas, agroenergia, manejo de florestas e da biodiversidade e a gestão territorial geocodificada e informatizada de todas as dimensões dos imóveis rurais, adotados em ampla escala, total ou parcialmente, em diversos biomas e por agricultores em situações socioeconômicas muito diferenciadas, num processo irreversível de ganhos em produtividade [12].

Quanto à preservação da vegetação nativa, qual agricultura no mundo dedica tanta área de seu território à preservação ou exige uma 


\section{Ocupação das Terras no Brasil}

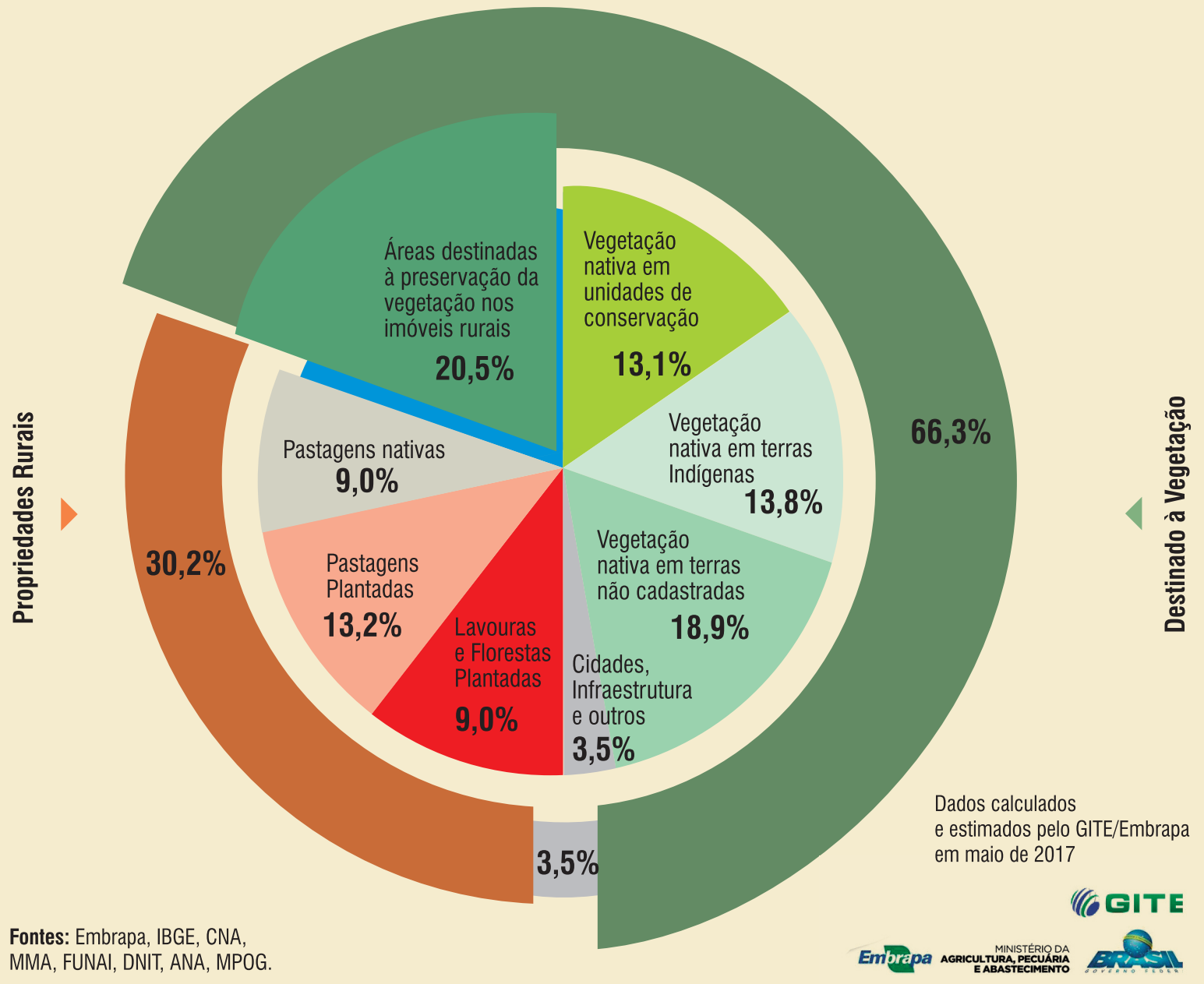

Figura 2. Uso e ocupação das terras no Brasil em porcentagem, 2016

contribuição, nesse sentido, da magnitude da exigida dos agricultores brasileiros? Não há no Brasil nenhuma categoria profissional que preserve tanto o meio ambiente como os agricultores.

E não há nenhuma instituição, secretaria, órgão federal ou estadual, empresa privada ou organização não governamental, salvo na Amazônia, que preserve tantas áreas de vegetação nativa como os produtores rurais: $20,5 \%$ do Brasil, contra $13 \%$ de todas as unidades de conservação juntas, ainda sem integrar os dados do Mato Grosso do Sul e do Espírito Santo.

Em média, a área de vegetação preservada nos imóveis rurais cadastrados no Sicar, até dezembro de 2016, correspondia a $47,7 \%$ de sua área total. Na média, os agricultores brasileiros exploram cerca de metade da área de seus imóveis rurais. As lavouras e florestas plantadas ocupam apenas $9 \%$ do território nacional. Metade do que já está destinado à preservação nos imóveis rurais, como atestam os dados do CAR.
Não surpreende que o Brasil seja considerado no mundo uma potência agrícola e ambiental: o total das áreas destinadas à preservação e proteção da vegetação nativa em unidades de conservação e terras indígenas (2.471 unidades e territórios), terras devolutas e imóveis rurais representam hoje mais de 66\% do território nacional (Figura 2).

O estado e a natureza da vegetação preservada nos imóveis rurais são muito variados em função dos biomas em que se encontram e de seu histórico de ocupação, uso e/ou recomposição. Alguns remanescentes ainda apresentam processos fitodinâmicos de reconstituição, com ou sem a intervenção dos produtores. Outros expressam situações de equilíbrios ecológicos metaestáveis no contexto territorial em que se inserem. Impedir a regressão ou a degradação da vegetação nativa nos imóveis rurais por fenômenos naturais (incêndios, presença de espécies invasoras) ou antrópicos (retirada de espécies, queimadas, uso indevido das áreas) é um grande desafio técnico e financeiro colocado aos produtores rurais. 
A gestão dessas áreas dedicadas à preservação pede um planejamento de longo prazo, investimentos financeiros de grande magnitude e um escopo de regras e processos de gestão que ainda não foram definidos, nem são legalmente autorizados (intervir em APP, por exemplo). Tudo isso é fundamental para que essas áreas de vegetação preservada nos imóveis rurais e que recobrem mais de 176 milhões de hectares, possam cumprir integralmente seu papel na sustentabilidade rural. Não basta abandoná-las sem uso. É preciso geri-las com tecnologias e recursos financeiros.

Valoração econômica, custo de manutenção e pagamento de serviços ambientais são três temas relevantes a serem associados com a gestão futura dessas áreas de vegetação preservada. Esse enorme esforço de preservação da vegetação nativa nos imóveis rurais beneficia toda a nação. $\mathrm{O}$ custo decorrente de imobilizar e manter essas áreas recai apenas sobre o produtor, sem contrapartida da sociedade, principalmente dos consumidores urbanos. Destes, os produtores esperam o justo reconhecimento, menos demonização de suas atividades e mais conhecimento de suas realidades e de sua contribuição ao meio ambiente.

Evaristo Eduardo de Miranda é doutor em ecologia pela Universidade de Montpellier (França) e chefe geral da Embrapa Monitoramento por Satélite. E-mail: evaristo.miranda@embrapa.br

\section{REFERÊNCIAS BIBLIOGRÁFICAS E FONTES}

1. Forman, R. T. T.; Godron, M. Landscape ecology. Wiley, 1986.

2. Gatrell, J. D.; Jensen, R. R (eds). Planning and socioeconomic applications, geotechnologies and the environment. Springer Science, 2009.

3. Opengeospacial. "Big processing of geospatial data", 2003. Disponível em: http://www.opengeospatial.org/blog/1866

4. Miranda, E. E. de. Agricultura no Brasil do século XXI. São Paulo, SP: Metalivros, 2013.

5. Gite - Grupo de Inteligência Territorial Estratégica da Embrapa, Campinas, 2017. Disponível em: https://www.embrapa.br/gite/sobre/index.html

6. Castro C. F. A. Gestão florestal no Brasil colônia. Universidade de Brasília, Brasília, 2002.

7. Brasil. Código Florestal Brasileiro. Lei 12.651 de 25 de maio de 2012. Disponível em: http://www.planalto.gov.br/ccivil_03/_ato20112014/2012/lei/l12651.htm

8. Buainain, A. M.; Alves, E.; Silveira, J. M. da; Navarro, Z. (org.). O mundo rural no Brasil do século 21: a formação de um novo padrão agrário e agrícola. Brasília, DF: Embrapa, 2014. 1182 p. Disponível em: https://www3.eco.unicamp.br/nea/images/arquivos/ O_MUNDO_RURAL_2014.pdf.

9. Gravina, M.. "Os benefícios dos transgênicos. Contribuições para o meio ambiente". Agroanalysis, 2010. Disponível em: http://www. agroanalysis.com.br/2/2010/conteudo-especial/especial-biotecnologia-os-beneficios-dos-transgenicos
10. Cadastro Ambiental Rural - CAR. Boletim Informativo do CAR, 2016. Disponível em: http://www.florestal.gov.br/documentos/car/boletim-do-car/2214-boletim-informativo-dezembro-de-2016/file

11. Miranda, E. E. de. "Primeiras análises do Cadastro Ambiental Rural (CAR) em São Paulo". Agroanalysis, 2017. Disponível em: http://www. agroanalysis.com.br/4/2017/conteudo-especial/faesp-agropecuaria-no-estado-de-sao-paulo

12. Alves E. "O que significam as medidas de produtividade da agricultura?". Revista de Economia e Agronegócio, 8, 3, 2010. Disponível em: http://www.revistarea.ufv.br/index.php/rea/article/view/172

13. Embrapa/CNPM. Miranda, E. E. de; Carvalho, C. A. de; Oshiro, O. T.; Martinho, P. R. R. Agricultura e preservação ambiental no Brasil: primeira análise do Cadastro Ambiental Rural, Campinas, 2017. Disponível em: https://www.cnpm.embrapa.br/projetos/car/

14. IBGE. Censo 2006. Conceituação das características divulgadas. Disponível em: http://www.ibge.gov.br/home/estatistica/economia/ agropecuaria/ censoagro/1995_1996/conceitos.shtm

15. Plangis - Plano de Gerenciamento Integrado da Sub-Bacia do Rio Salitre, UFBA, 2003 in http://www.grh.ufba.br/download/Rel\%20 Final\%20Salitre-\%20Res\%20Executivo\%20-\%2025-02-2003.pdf

16. SFB - Serviço Florestal Brasileiro. Números do Cadastro Ambiental Rural. Disponível em: http://www.florestal.gov.br/numeros-do-car 